\title{
PLANEJAMENTO SISTEMÁTICO DE LAYOUT (PSL): ANÁLISE DO LAYOUT DE UMA EMPRESA PRODUTORA DE PNEUS RECAPADOS
}

\section{SYSTEMATIC LAYOUT PLANNING (PSL): ANALYSIS OF THE LAYOUT OF A COMPANY PRODUCER OF TIRE RECAP}

\author{
Vitor William Batista Martins \\ Universidade Federal do Pará \\ Mestrando do Programa de Pós-Graduação em Engenharia Civil \\ Departamento de Engenharia Civil, Instituto de Tecnologia, Av. Augusto Corrêa, 01, CEP - \\ 66075-970, Guamá, Belém, Pará, Brasil. \\ vitor_engenharia@hotmail.com

\section{Prof. Felipe Fonseca Tavares de Freitas} \\ Universidade da Amazônia \\ Mestre em Engenharia de Produção e Sistemas pela PUC-PR \\ Departamento de Engenharia de Produção, Centro de Ciências Exatas e Tecnologia, Av. \\ Alcindo Cacela, 287, CEP - 66060-902 Umarizal, Belém, Pará, Brasil. \\ fftfreitas@gmail.com
}


RESUMO: Atualmente observa-se a crescente preocupação por partes das empresas em relação à saúde e bem estar físico do trabalhador. Este artigo analisou o layout atual de uma empresa produtora de pneus recapados, levando em consideração suas deficiências em relação à segurança do trabalhador no chão de fábrica e a movimentação de materiais e pessoas. $\mathrm{O}$ objetivo do artigo é propor um layout otimizado, através das considerações do método PSL e as considerações de acordo com as Normas Regulamentadoras 12 e 26, visando à movimentação do trabalhador e materiais entre o maquinário no chão de fábrica, com o intuito de proporcionar a segurança adequada para o trabalhador e satisfação em exercer sua função no trabalho.

Palavras-chave: Ergonomia. Planejamento Sistemático de Layout. Layout otimizado.

ABSTRACT: Currently there is a growing concern for shares of companies in relation to health and well being of the worker. This paper analyzed the current layout of a producer of retread tires, taking into consideration their shortcomings in relation to worker safety on the factory floor and moving materials and people. The aim of this paper is to propose a streamlined layout, through the PSL method considerations and considerations in accordance with the Rules Regulating twelve and twenty six in order to move materials between the worker and the machinery on the factory floor, in order to provide adequate security for the worker and satisfaction in performing their job function.

Keywords: Ergonomics. Systematic Layout Planning. Layout optimized. 


\section{INTRODUÇÃO}

Atualmente observa-se a crescente preocupação por partes das empresas em relação à saúde e bem estar físico do trabalhador. Isso decorre devido às organizações terem começado a perceber o aumento da produtividade e da qualidade dos serviços prestados, pelo simples fato do trabalhador sentir-se bem (disposto) e seguro em seu ambiente de trabalho.

A empresa onde foi feito o estudo caracteriza-se por fazer a reconstituição de pneus defasados/gastos, conhecida como recapagem de pneus, para tal serviço utiliza-se de um maquinário específico em seu chão de fábrica e uma mão de obra especializada para a operação das máquinas.

A empresa analisada encontra-se localizada na Região Metropolitana de Belém, estado do Pará, no município de Ananindeua, possui uma estrutura de galpão de $350 \mathrm{~m}^{2}$. Com uma quantidade de vinte trabalhadores, entre operadores de máquinas, supervisores e gerente, a empresa conta também com oito máquinas em seu chão de fábrica.

Este artigo analisou o layout atual de uma empresa produtora de pneus recapados. Para o projeto e planejamento do layout proposto, levou-se em consideração o método PSL e as Normas Regulamentadoras (NR's) 12 e 26, visando à movimentação do trabalhador e materiais entre o maquinário no chão de fábrica. Com o objetivo de proporcionar a segurança adequada para o trabalhador e satisfação em exercer sua função no trabalho.

$\mathrm{O}$ artigo encontra-se estruturado da seguinte forma: a seção 2 apresenta o referencial teórico utilizado, ou seja, às teorias que serviram para dar um embasamento na elaboração do artigo; a seção 3 mostra a metodologia aplicada detalhando o passo a passo de como foi feito o estudo e classificando formal e cientificamente o artigo; a seção 4 mostra os resultados obtidos com a pesquisa e na seção 5 observa-se de maneira sucinta a conclusão do estudo.

\section{REFERENCIAL TEÓRICO}

Para um estudo detalhado sobre o assunto foram consultadas diversas referências, a fim de se obter um maior embasamento/conhecimento das definições e conceitos relacionados ao tema. Por meio desta seção serão apresentadas as referências utilizadas na pesquisa, que após uma leitura vertical e posteriormente horizontal serviu para proporcionar ao artigo um embasamento adequado.

\subsection{Planejamento Sistemático de Layout}

O Planejamento Sistemático do Layout (PSL) consiste de uma estruturação de fases, de um modelo de procedimentos e de uma série de convenções para identificação, avaliação e 
visualização dos elementos e das áreas envolvidos no planejamento (MUTHER, 1978). Em suma, a metodologia do PSL é uma ferramenta que irá auxiliar indivíduos na tomada de decisão quanto ao melhor posicionamento das instalações, máquinas, equipamentos e pessoal na linha de produção (COSTA, 2004).

O PSL é um procedimento que visa identificar dentre vários cenários aquele que mais se ajusta às necessidades estabelecidas pela empresa (YANG et al., 2000). De acordo com Muther (1978), a metodologia do Planejamento Sistemático do Layout (PSL) é constituída de quatro fases: quais seriam: localização da área, arranjo físico geral, arranjo físico detalhado e implantação.

Na primeira fase, determina-se a localização da área das instalações. Na segunda fase, o arranjo físico estabelece a posição relativa entre as diversas áreas. A terceira fase envolve a localização de cada máquina, equipamento e estabelece a localização de cada uma das características físicas específicas da área, incluindo todos os suprimentos e serviços. $\mathrm{Na}$ quarta e última fase, será planejado cada passo de implantação, incluindo a captação de capital e deslocamento das máquinas, equipamentos e recursos, a fim de que sejam instalados conforme o planejado (MUTHER, 1978 apud COSTA, 2004).

A metodologia PSL auxilia o tomador de decisão neste processo, e uma modificação eficaz do layout pode resultar na redução do custo, redução da movimentação dos materiais dentro do processo, racionalizando o fluxo de pessoas e dos produtos proporcionando um aumento na produtividade e eficiência obtido a partir de uma melhor utilização do espaço disponível (MUTHER, 1978).

A alteração de um layout necessariamente irá impactar o sistema produtivo, podendo afetar uma organização positiva ou negativamente. Essa alteração deverá sempre estar em função de um objetivo que irá nortear o planejamento do novo layout, por exemplo, minimização do tempo de movimentação interna, racionalização do fluxo, aumento da eficiência da mão-de-obra e/ou na melhoria da comunicação entre as áreas envolvidas no sistema produtivo (KOSTROW, 1996).

De acordo com Borges (2001), o layout de uma fábrica é a disposição física dos equipamentos industriais, incluindo o espaço necessário para movimentação de material, armazenamento, mão-de-obra indireta e todas as outras atividades e serviços dependentes, além do equipamento de operação e o pessoal que o opera. Layout, portanto, pode ser uma instalação real, um projeto ou um trabalho.

De acordo com a Norma Regulamentadora 12, que trata sobre máquinas e equipamentos, os pisos dos locais de trabalho onde se instalam máquinas e equipamentos 
devem ser vistoriados e limpos, sempre que apresentarem riscos provenientes de graxas, óleos e outras substâncias que os tornem escorregadios, as áreas de circulação e os espaços em torno de máquinas e equipamentos devem ser dimensionados de forma que o material, os trabalhadores e os transportadores mecanizados possam movimentar-se com segurança, a norma diz também que: a distância mínima entre máquinas e equipamentos deve ser de $0,60 \mathrm{~m}$ (sessenta centímetros) a $0,80 \mathrm{~m}$ (oitenta centímetros), a critério da autoridade competente em segurança e medicina do trabalho.

Além da distância mínima de separação das máquinas, deve haver áreas reservadas para corredores e armazenamento de materiais, devidamente demarcadas com faixa nas cores indicadas pela NR 26, cada área de trabalho, situada em torno da máquina ou do equipamento, deve ser adequada ao tipo de operação e à classe da máquina ou do equipamento que atende.

De acordo com Slack et al. (1996), o arranjo físico de uma operação produtiva preocupa-se com a localização física dos recursos de transformação. De acordo com Mason (1989), o layout de uma planta é um objeto tradicional da engenharia industrial que trabalha com relações especiais e sensitivas. É a atividade que atualmente exige "sangue e suor" para a adaptação da estratégia de manufatura. Além disso, um layout tem muitas implicações práticas e estratégicas. Segundo Monks (1987), um bom layout permite que os materiais, o pessoal e as informações fluam de uma forma eficiente e segura. Logo, as escolhas de layout podem auxiliar na comunicação de estratégias de produto e prioridades competitivas.

De acordo com Couto (2006), deve-se prever espaços mínimos compatíveis com as necessidades das pessoas segundo o tipo de atividade realizada, não devendo a mesma ser menor que $6 \mathrm{~m}^{2}$, posicionar os postos de trabalho com alto desempenho visual mais próximos da luz natural.

Percebe-se que as referências utilizadas para embasar o artigo proporcionaram um melhor entendimento do tema. De acordo com os autores citados, o PSL se mostra uma ferramenta de fundamental importância para obter um layout mais próximo do ótimo possível e em paralelo as considerações das Normas Regulamentadoras 12 e 26 se tornam vertentes relevantes na aplicação do PSL.

\section{METODOLOGIA}

Na seção 3 é aborda a metodologia utilizada no estudo. Foi aplicada uma metodologia objetiva que se baseia na análise, principalmente, do fluxo do processo produtivo por meio da disposição das instalações necessárias ao processo e o enfoque dado à abordagem da questão 
de segurança do trabalhador. Resultando numa visão crítica em busca de problemas e erros do projeto de arranjo físico atual.

\subsection{Procedimentos para elaboração do artigo}

O presente estudo partiu da análise do processo produtivo por meio do acompanhamento in loco e de entrevistas aplicadas aos envolvidos com a produção. Em seguida, fez-se uma descrição textual das condições de trabalho observadas, abordando uma série de detalhes relacionados aos procedimentos operacionais adotados e ao fluxo de materiais percebido.

Foram observados os seguintes aspectos: alocação dos postos de trabalho, o acesso dos operadores no chão de fábrica, a movimentação de pessoas e materiais, a localização das matérias-primas, atendimento aos dispositivos legais, ou seja, análise as NR's e verificar os procedimentos contra incêndios.

Fez-se um levantamento de varias bibliografias pertinentes aos métodos pretendidos na utilização da elaboração do layout otimizado, a fim de desenvolver uma fundamentação teórica sólida para a realização/aplicação do estudo de caso. Do ponto de vista teórico/científico o artigo classificou-se como qualitativo.

Em seguida se realizou um levantamento da atual situação de trabalho na empresa, levando em consideração o tempo de serviço dos trabalhadores, a satisfação em exercer sua função e a segurança no ambiente de trabalho, posteriormente foi feito o desenho do layout atual da empresa retratando suas inadequações.

Foram definidos os métodos a serem utilizados para a produção do layout ergonomicamente correto, que são: o Método PSL e as considerações da Norma Regulamentadora 12 e Norma regulamentadora 26, a fim de proporcionar maior facilidade de movimentação dos materiais no chão de fábrica e, consequentemente, contribuir para um maior nível de segurança a eles.

Também foram realizadas entrevistas com os trabalhadores, seguidas pelas medições das áreas totais em metros quadrados $\left(\mathrm{m}^{2}\right)$, as medições das máquinas para saber o espaço que as mesmas demandam, foi feito o levantamento detalhado das inadequações com relação à segurança do trabalhador.

Para a elaboração do layout ergonomicamente correto levou-se em consideração as 6 etapas do método PSL - Simplificado, onde foi feito o passo a passo de cada etapa de acordo com as definições e exigências necessárias para tal elaboração. 
De posse de todas as informações necessárias à reflexão do layout, foi produzido um diagnóstico, abordando todos os erros e problemas encontrados, com vista a demonstrar a importância da elaboração de um projeto de arranjo físico para o caso abordado.

\section{RESULTADOS}

A seguir na seção 4, verificam-se os resultados obtidos, a seção 4.1 apresenta o layout real da empresa, mostrando suas características e fazendo suas considerações com relação aos trabalhadores. A seção 4.2, mostra os resultados obtidos com a aplicação dos métodos, visando os layouts propostos e seção 4.3 mostra o layout escolhido com seus indicadores relevantes.

\subsection{Layout real}

É importante retratar o layout real (atual) da empresa, pois ajuda a obter uma ideia real do ambiente de trabalho e o mais importante ajuda a identificar as possíveis falhas de projeto na definição de layout. De acordo com o levantamento feito por meio de entrevistas com os trabalhadores da empresa, muitos não se consideram seguros no chão de fábrica.

O layout real é composto por oito máquinas no chão de fábrica, a empresa trabalha com duas matérias primas que são: cola e a banda, a máquina 1 é a máquina de exame, a máquina 2 é a de raspagem, a máquina 3 recebe o nome de escariador, a 4 é a cabine de cola, a 5 é a responsável pelo corte de banda, a máquina 6 é conhecida como roletadeira 1 e a 7 é a roletadeira 2, as máquinas 8 e 9 são as vulcanizadoras.

De acordo com a verificação feita, podemos observar as dimensões relevantes para a definição do layout proposto, segue as dimensões das máquinas no chão de fábrica, conforme Tabela 1.

\begin{tabular}{c|ccc}
\hline Máquinas & Comprimento/m & Largura/m & Área EM m$^{\mathbf{2}}$ \\
\hline Exame & 1,34 & 1,60 & 2,14 \\
Raspagem & 1,32 & 1,97 & 2,60 \\
Escariador & 1,55 & 0,95 & 1,47 \\
Cabine de cola & 1,25 & 1,75 & 2,18 \\
Corte de banda & 4,85 & 2,20 & 10,67 \\
Roletadeira & 1,30 & 3,90 & 5,07 \\
2 vulcanizadoras & 4,40 & 5,10 & 22,44 \\
Estoque de mat. prima & 10,00 & 4,97 & 49,70 \\
Entrada/recepção & 1,57 & 3,00 & 4,71 \\
Total & 26,01 & 22,44 & 100,98 \\
Área total do galpão & 35 & 10 & 350 \\
\hline
\end{tabular}

Tabela 1 - Dimensões das máquinas

Fonte: Autores (2010) 
De acordo com o layout real da empresa, pode-se perceber que é bem distribuído o posicionamento das máquinas com relação ao processo produtivo, é possível identificar que o posicionamento das máquinas foi definido levando em consideração as etapas do processo de produção, esquecendo-se de levar em consideração o bem estar e a segurança do trabalhador no chão de fábrica, assim como o fluxo de materiais. Retrata certa desorganização de materiais utilizados no processo produtivo, verificam-se também riscos ao trabalhador, como o pouco espaço entre máquinas e a desorganização dos pneus a serem recapados. As medidas em $\mathrm{m}^{2}$ são retratadas de acordo com a Figura 1.

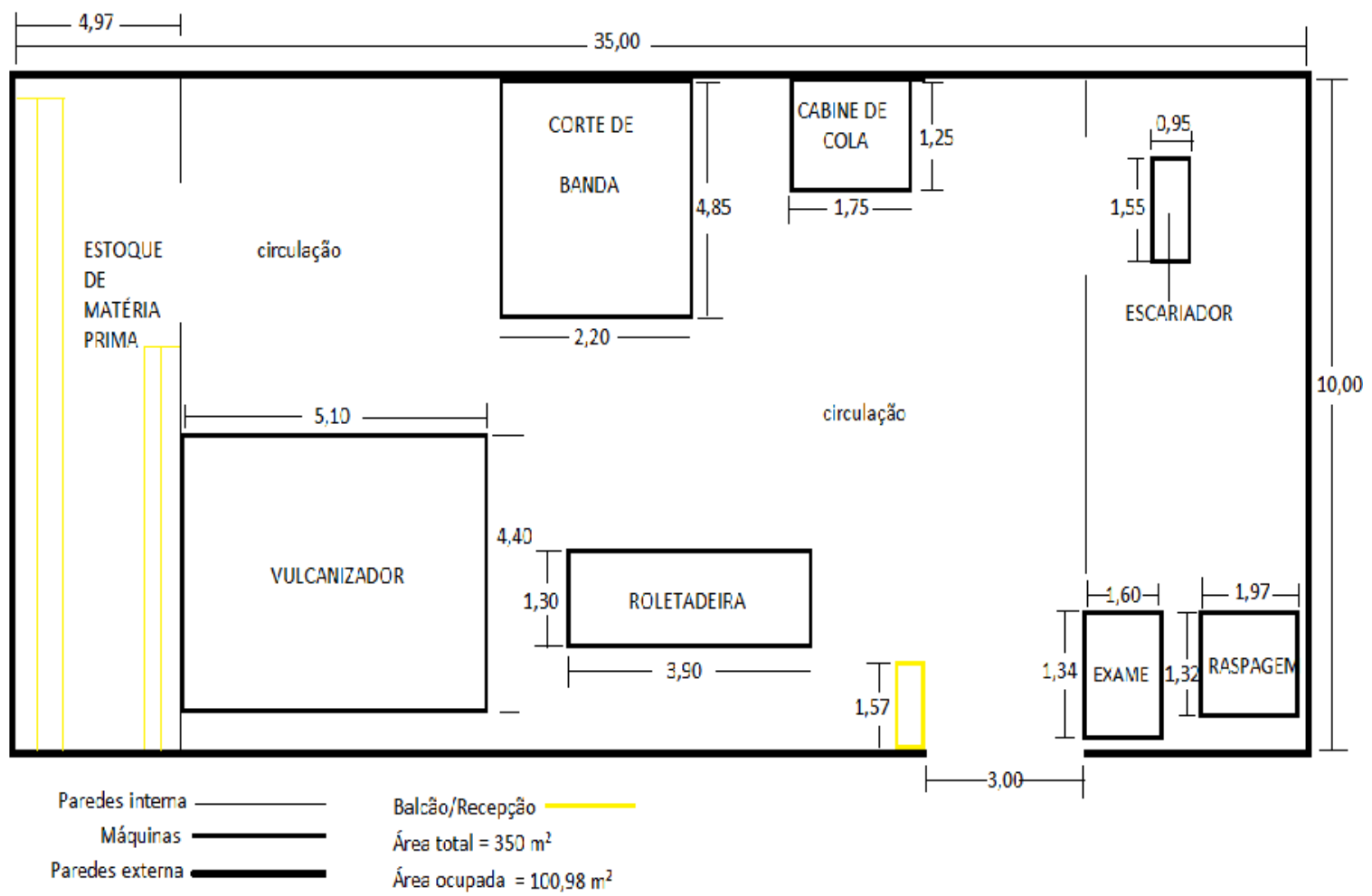

Figura 1 - Layout real com suas respectivas medidas

Fonte: Autores (2010)

\subsection{Layouts propostos (otimizados)}

É fundamental para as empresas atualmente possuir um layout adequado para seu processo de produção. Pois os benefícios são muito significativos com relação a sua produtividade, a satisfação de trabalhar em um ambiente adequado e principalmente a segurança dos seus trabalhadores.

Com base em tais benefícios foi realizado um levantamento para definição do posicionamento de máquinas no chão de fábrica, a fim de obter um Layout Ergonomicamente Correto. Com isso proporcionando alguns benefícios aos trabalhadores tais como: facilidade 
de locomoção no chão de fábrica, segurança no ambiente de trabalho e evitando o fluxo desnecessário de materiais.

Para tal ajuste de layout foi utilizado o Método PSL para definição de posicionamento dos maquinários e as considerações da Norma Regulamentadora 12. O que definiu um posicionamento adequado da máquina levando em consideração vários fatores, que tem como objetivo a facilidade de locomoção/movimentação dos trabalhadores e materiais no chão de fábrica.

De acordo com o apresentado na figura 1, foram definidos para os layouts propostos 4 pontos que mereceram grande atenção que são:

a) $\mathrm{O}$ melhor aproveitamento de espaço para o fluxo de pessoas e materiais com segurança;

b) A necessidade de uma porta de saída para o produto final próximo do ultimo maquinário utilizado no processo, facilitando o escoamento do produto final e evitando o seu refluxo pelo chão de fábrica;

c) Mudança de localização do estoque de matéria prima (banda) para mais próximo da máquina que utiliza tal material, e;

d) Uma maior comunicação visual como marcações luminosas no chão para advertência de áreas com perigo ao trabalhador.

Para a elaboração dos layouts propostos, foram realizadas as 6 etapas existentes no método PSL simplificado. De acordo com o resultado do Diagrama de Relações, primeira etapa do método, foi definido o grau de proximidade que as atividades devem ter entre si, chegou-se no "layout proposto A" a um resultado de 36 decisões individuais e no "layout proposto B" um resultado de 45 decisões individuais de como uma atividade se relaciona com a outra. Os resultados podem ser verificados no Apêndice I.

De acordo com o levantamento feito das dimensões dos maquinários partiu-se para a etapa 2, onde foram definidas as necessidades de espaço para a elaboração dos layouts propostos. Tal definição é de fundamental importância para a utilização do espaço de maneira correta. Pode-se verificar os resultados da definição de espaço conforme mostra o Apêndice II.

$\mathrm{Na}$ etapa 3 foi possível relacionar as atividades no diagrama, sendo tal etapa é de fundamental importância porque ajuda a ajustar o layout para o mais próximo possível do arranjo ideal. Nessa etapa ocorre a esquematização do melhor ajuste das varias relações classificadas. A realização da etapa está ilustrada no Apêndice III. 
A etapa 4 consiste em desenhar os layouts de relação de espaço, possibilita conseguir as dimensões específicas e permite que sejam verificadas as características físicas, tais como colunas, formas de acesso, paredes exteriores mínimas, ajustes no local, entre outros. O Apêndice IV mostra a realização dessa etapa.

Conforme a metodologia PSL e as considerações da NR12 foi possível fazer uma avaliação dos arranjos físicos propostos, passo 5 do PSL, para que possa ser tomada a melhor decisão na definição do layout final. Uma lista de vantagens e desvantagens não fornece um embasamento suficiente, por isso tornou-se necessário a elaboração da avaliação do arranjo físico. Segundo como mostra o Apêndice V.

Por ultimo, fez-se o detalhamento do layout, mostrando as características adquiridas pelos layouts propostos (estoque enxuto, faixas luminosas de advertência, fácil circulação de pessoas e materiais), com o objetivo de trazer melhorias tanto para a produtividade da empresa quanto para o trabalhador do chão de fábrica. Como pode ser visualizado nas Figuras 2 e 3 .

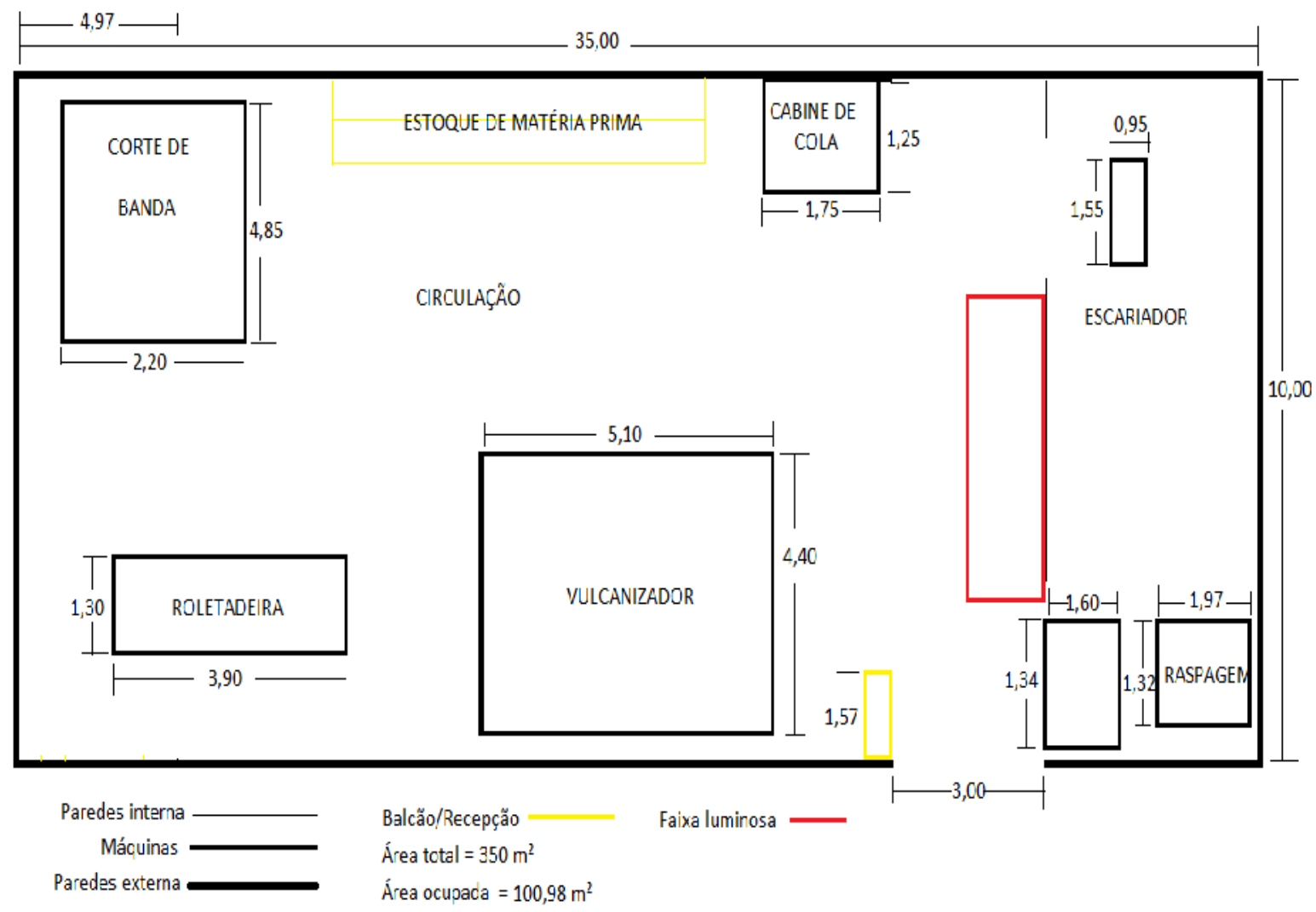

Figura 2 - Layout proposto A

Fonte: Autores (2010) 


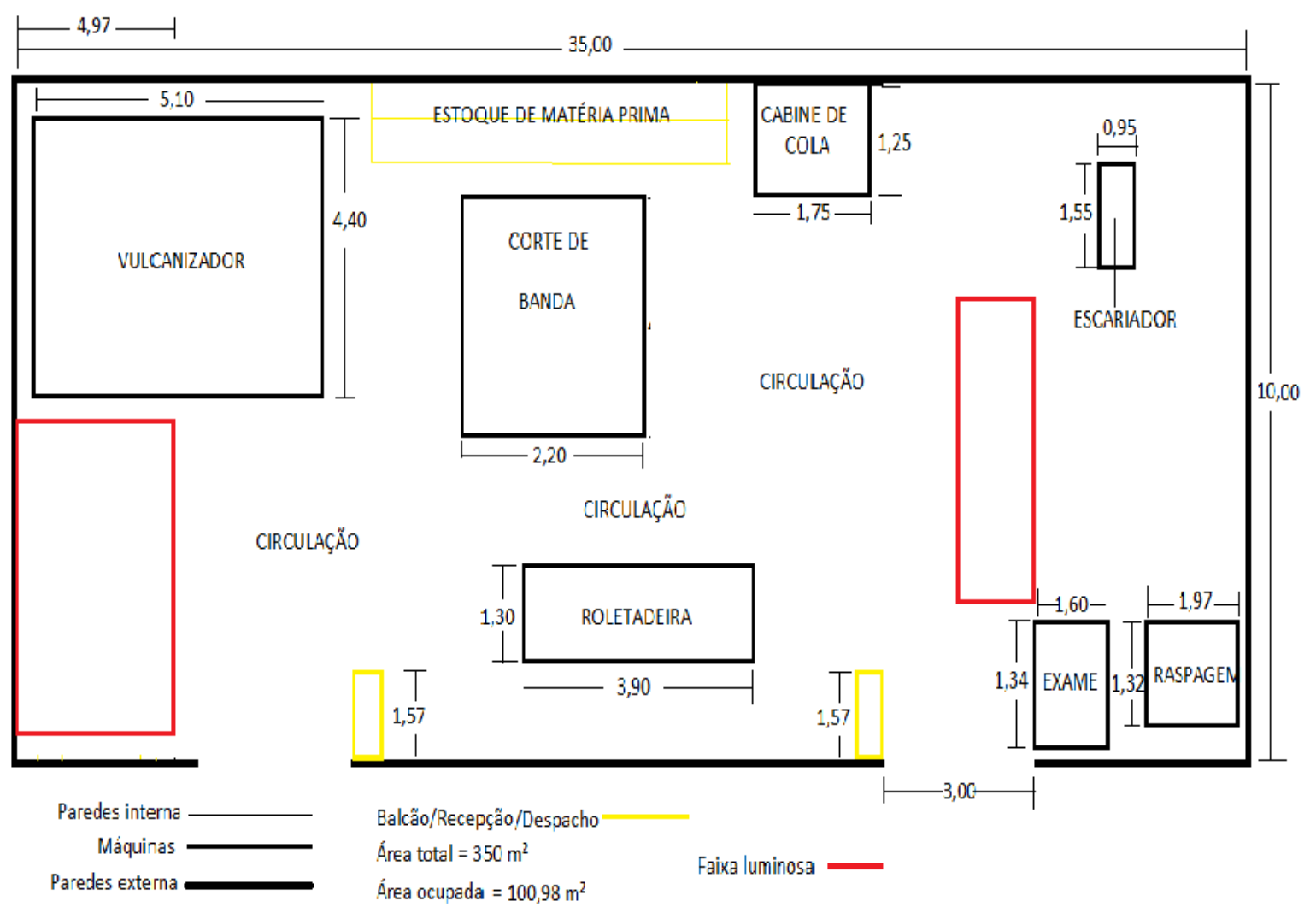

Figura 3 - Layout proposto B

Fonte: Autores (2010)

\subsection{Layout escolhido}

De acordo com as duas opções apresentadas como layouts propostos, foi escolhido apenas um layout final, por meio de entrevistas entre os trabalhadores e a opinião da alta gerência da empresa, opinião esta que se fez de acordo com o indicado pelos elaboradores do layout, não se pode esquecer também de levar em consideração para a escolha os resultados da etapa 5 do PSL.

Alguns indicadores relevantes, cruciais para a tomada de decisão, são apresentados: a entrevista foi realizada com 10 trabalhadores/operadores do chão de fábrica para saber qual arranjo físico eles preferiam, o "layout proposto A" ou o "layout proposto B", 7 preferiam o "layout B", 2 responderam que tanto faz um ou o outro e 1 preferiu o "layout A". Portanto, $70 \%$ dos trabalhadores optaram pelo "layout B".

Dentre os dois elaboradores do layout, a decisão foi unânime de que o layout teria que ser o "layout B", pois com uma entrada e uma saída o fluxo de materiais e principalmente o escoamento do produto final ficaria melhor, e também a etapa cinco (Apêndice V) do PSL foi crucial para a decisão, pois mostra de maneira clara as vantagens do "layout B". 


\section{CONCLUSÃO}

O PSL foi de fundamental importância na elaboração do artigo, pois mostrou resultados satisfatórios e embasados para a escolha da configuração do layout "adequado", conforme os conceitos da NR12 e NR26 foram surgindo ideias importantes para o layout contribuindo nas tomadas de decisões.

Para a elaboração do estudo de caso, foram encontrados alguns obstáculos, como: a disponibilidade dos trabalhadores para a realização da entrevista, a falta de informações referentes ao maquinário (peso) e o difícil acesso para informações da alta gerência.

Foi observado com os resultados obtidos que a maioria dos trabalhadores/operários demonstraram satisfação diante dos layouts propostos, mesmo assim ainda há trabalhadores resistentes ao novo layout proposto, classificados como trabalhadores conservadores.

Os resultados mostraram um layout que se caracteriza como um layout do tipo U, este tipo de arranjo possui características muito relevantes para o aumento da produtividade da empresa como: grande flexibilidade de pessoas, equilíbrio fáceis, boa comunicação entre os trabalhadores e consequentemente dos setores dos processos e um bom fluxo de materiais.

As vantagens desse tipo de layout em U são inúmeras, onde se destacam: uma menor interferência nas áreas de circulação, a facilidade para se trabalhar em grupo, a facilidade de retrabalho e a movimentação e o manuseio de materiais de forma simples.

\section{REFERÊNCIAS}

COSTA, A. J. Otimização do layout de produção de um processo de pintura de ônibus. Dissertação (Mestrado Profissionalizante em Engenharia). Universidade Federal do Rio Grande do Sul (UFRGS), Escola de Engenharia: Programa de Pós-Graduação em Engenharia de Produção, Porto Alegre, 2004.

MASON, E. R. Plant Layout requirements for the factory of the future. AIPE Facilities Management, Operation and Engineering. January-February, v.16, p. 32-35, 1989.

MONKS, J. G. Administração da Produção. São Paulo: Mgraw-Hill, 1987.

MUNTHER, R.; WHEELER, J. Planejamento Simplificado de Layout, $2^{\text {o }}$ Edição, 2008.

SLACK, N. Administração da Produção. 2. ed. São Paulo: Atlas, 2002.

SLACK, N.; CHAMBERS, S.; HARLAND, C. Administração da Produção. São Paulo: Atlas, 1996.

KOSTROW, P. The Facilities Planning Process. Facilities Planning. Executive, p. 10-14, May-June, 1996. 
YANG, T.; SU, C. T.; HSU, Y. R. Systematic layout planning: a study on semiconductor wafer fabrication facilities. International Journal of Operations Production Management, v. 20, n. 11, p. 1359-1371, 2000. 


\section{APÊNDICE I - DIAGRAMA DE RELAÇÕES}

Planta: Fábrica pneus recapagem - Projeto: Layout máquinas

Feito por: Vitor Martins

Data: 30/05/2010

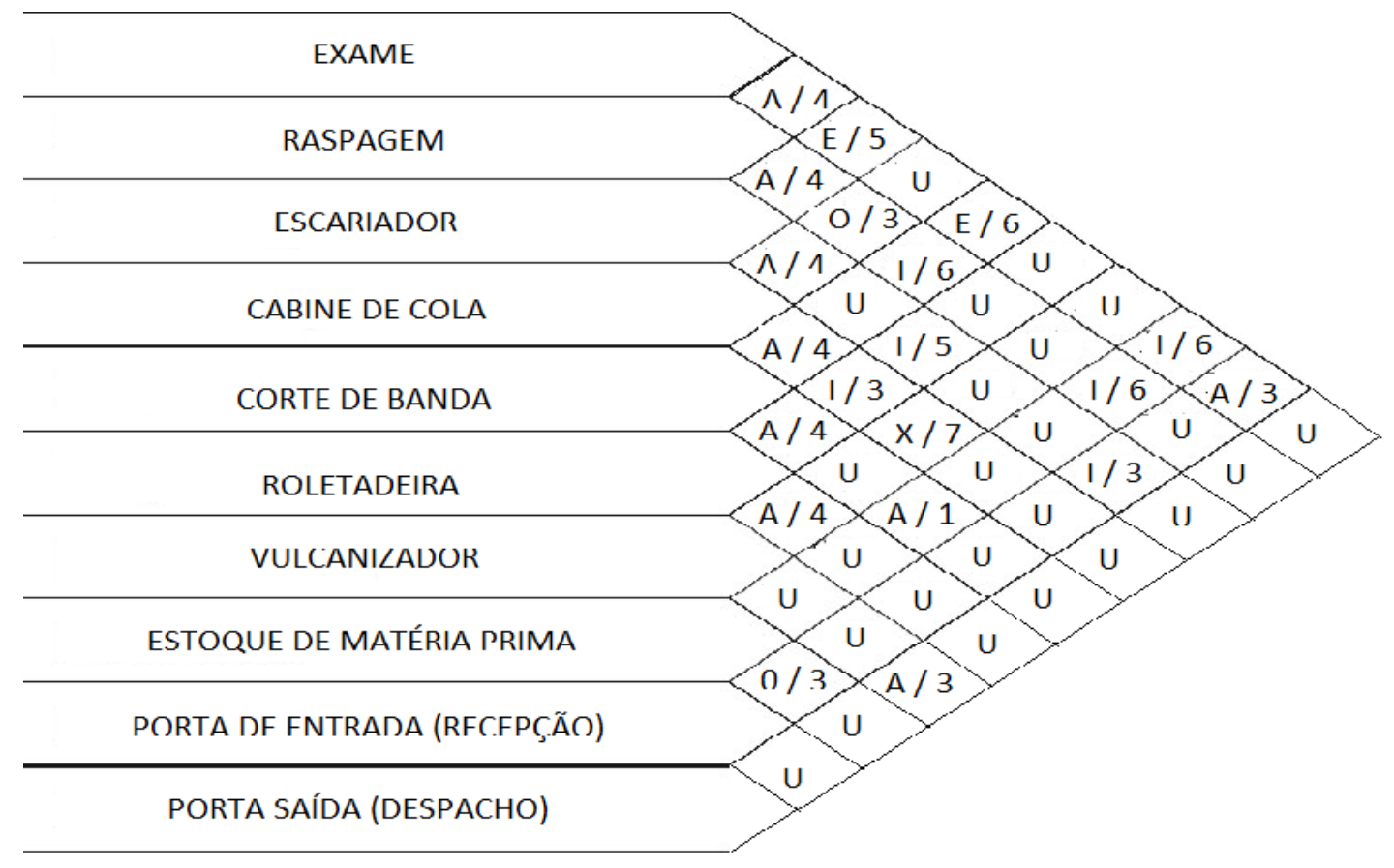

GRAU DE PROXIMIDADES

\begin{tabular}{|c|c|c|}
\hline VALOR & PROXIMIDADES & $\mathrm{N}^{\mathbf{o}}$ de classificações \\
\hline $\mathrm{A}$ & Absolutamente necessário & 9 \\
\hline $\mathrm{E}$ & Especialmente importante & 6 \\
\hline $\mathrm{I}$ & Importante & 2 \\
\hline $\mathrm{O}$ & Proximidade Normal & 25 \\
\hline $\mathrm{U}$ & Sem importância & 1 \\
\hline X & Não desejável & 45 \\
\hline Total: $\mathrm{Nx}(\mathrm{N}-1) / 2$ & & \\
\hline
\end{tabular}

Razão por traz dos valores de "proximidades":

\begin{tabular}{|c|c|}
\hline Cód. & Razão \\
\hline 1 & Equipamento que utiliza a matéria prima por primeiro \\
\hline 2 & Movimento de pessoas \\
\hline 3 & Movimento de materiais \\
\hline 4 & Processo de produção contínuo \\
\hline 5 & Produto com produção diferente \\
\hline 6 & Fluxo de informação \\
\hline 7 & Risco de incêndio \\
\hline
\end{tabular}

Fonte: Autores, 2010. 


\title{
APÊNDICE II - DIMENSIONAMENTO DE ÁREA
}

\author{
FICHA DAS ÁREAS E CARASTERÍSTICAS DAS ATIVIDADES
}

ATIVIDADES <----Características Físicas Necessárias----->

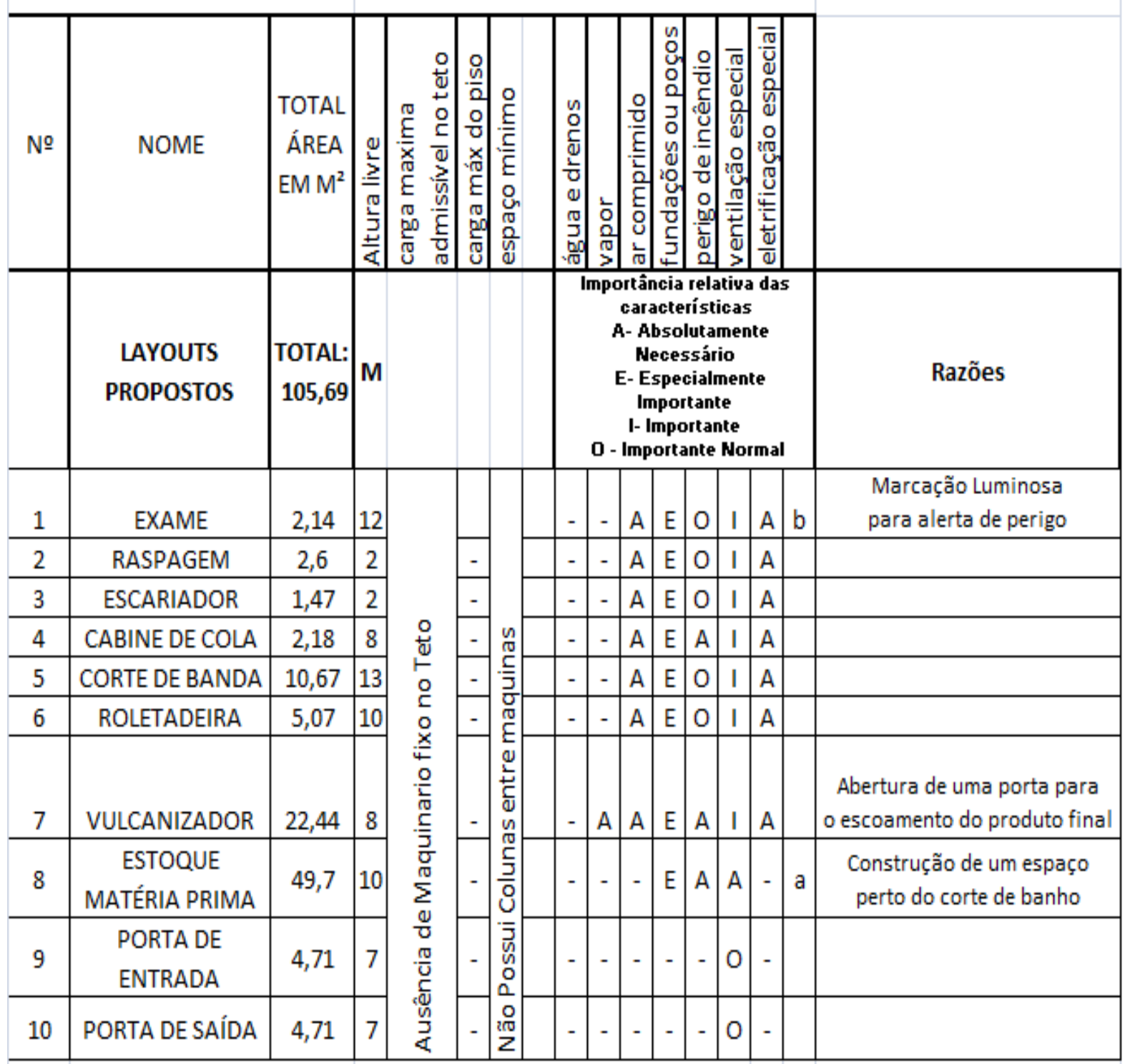

a) Área cercada por telas metálicas

Referências

e observaçōes

b) Área com marcações luminosas no chão

Fonte: Autores, 2010. 


\section{APÊNDICE III - RELAÇÕES DAS ATIVIDADES NO DIAGRAMA}

DIAGRAMA № 1:

A's e E's

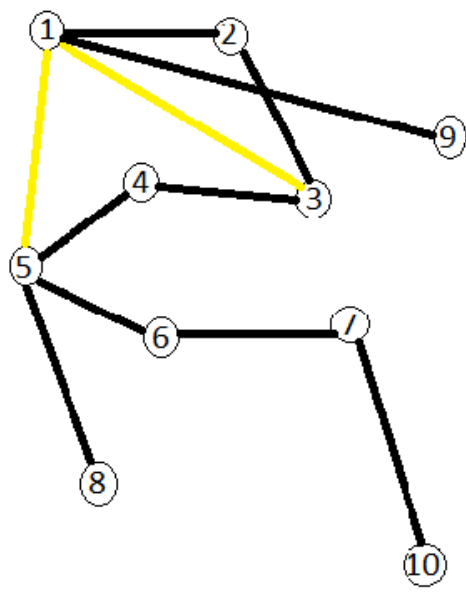

$\mathrm{A}^{\prime} \mathrm{s}=$
$\mathrm{E}^{\prime} \mathrm{s}-$

\author{
DIAGRAMA № 2 \\ ADICIONAR OSI'S
}

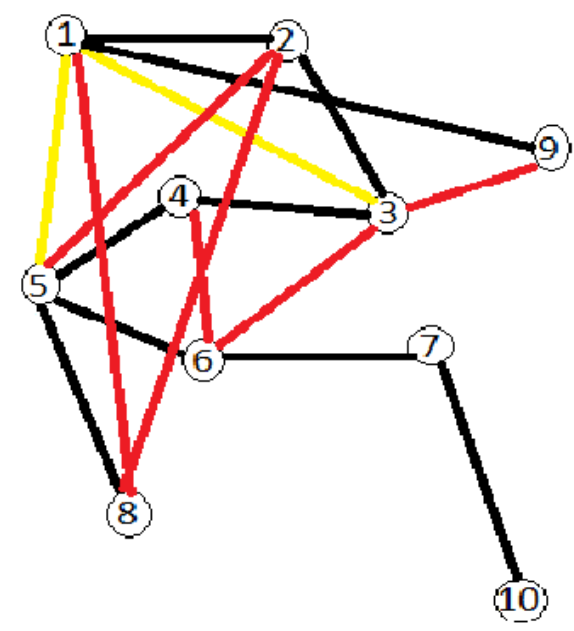

I's =
ADICIUNAK US O'S e X'S

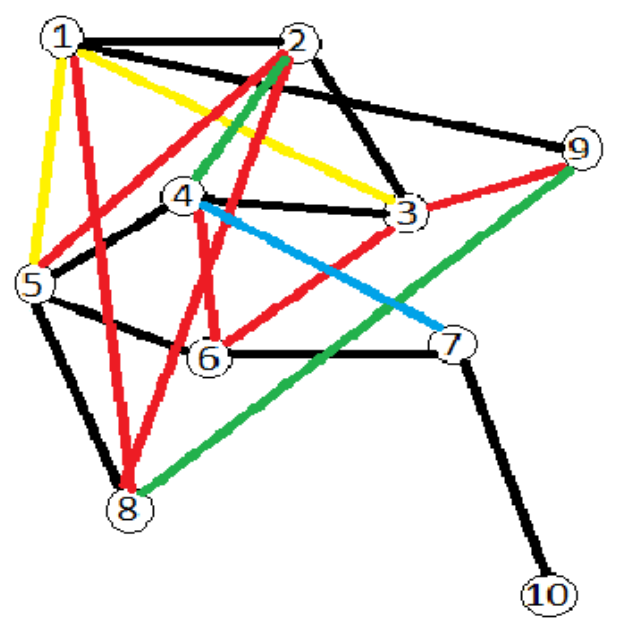

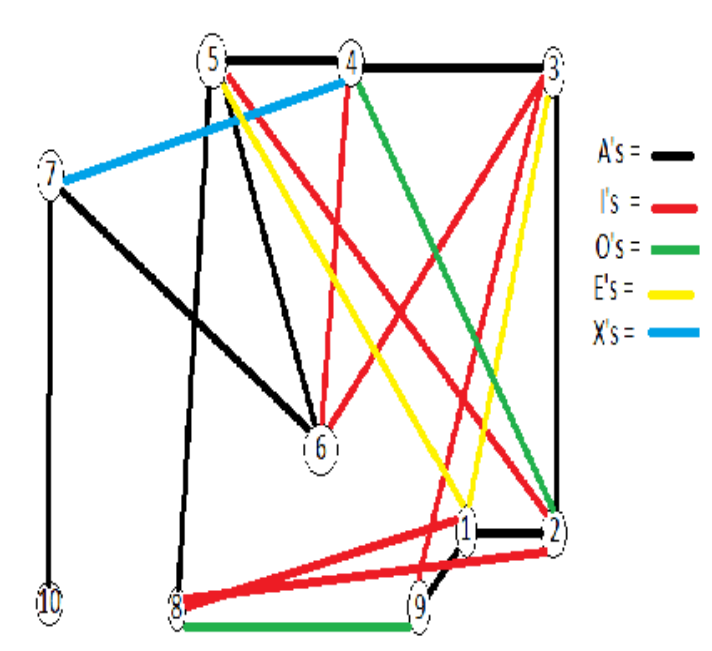

O's $=$
$X^{\prime} \cdot s=$
1) $2,14 \mathrm{~m}^{2}$
2) $2,60 \mathrm{~m}^{2}$
3) $1,47 \mathrm{~m}^{2}$
4) $2,18 \mathrm{~m}^{2}$
5) $10,67 \mathrm{~m}^{2}$
6) $5,07 \mathrm{~m}^{2}$
7) $22,44 \mathrm{~m}^{2}$
8) $49,70 \mathrm{~m}^{2}$
9) $4,71 \mathrm{~m}^{2}$
10) $4,71 \mathrm{~m}^{2}$
TOTAL $=105,69 \mathrm{~m}^{2}$

Fonte: Autores, 2010. 


\section{APÊNDICE IV - DESENHO DOS LAYOUTS RELAÇÃO DE ESPAÇO}

\section{LAYOUT PROPOSTO A:}

MÁCLUINAS =

PHAAIILLIRA LSIOU. MAI. PRIIMA $=$

RALICÄก DF RFCFPCÖßO

FAIXA LUMINOSA -

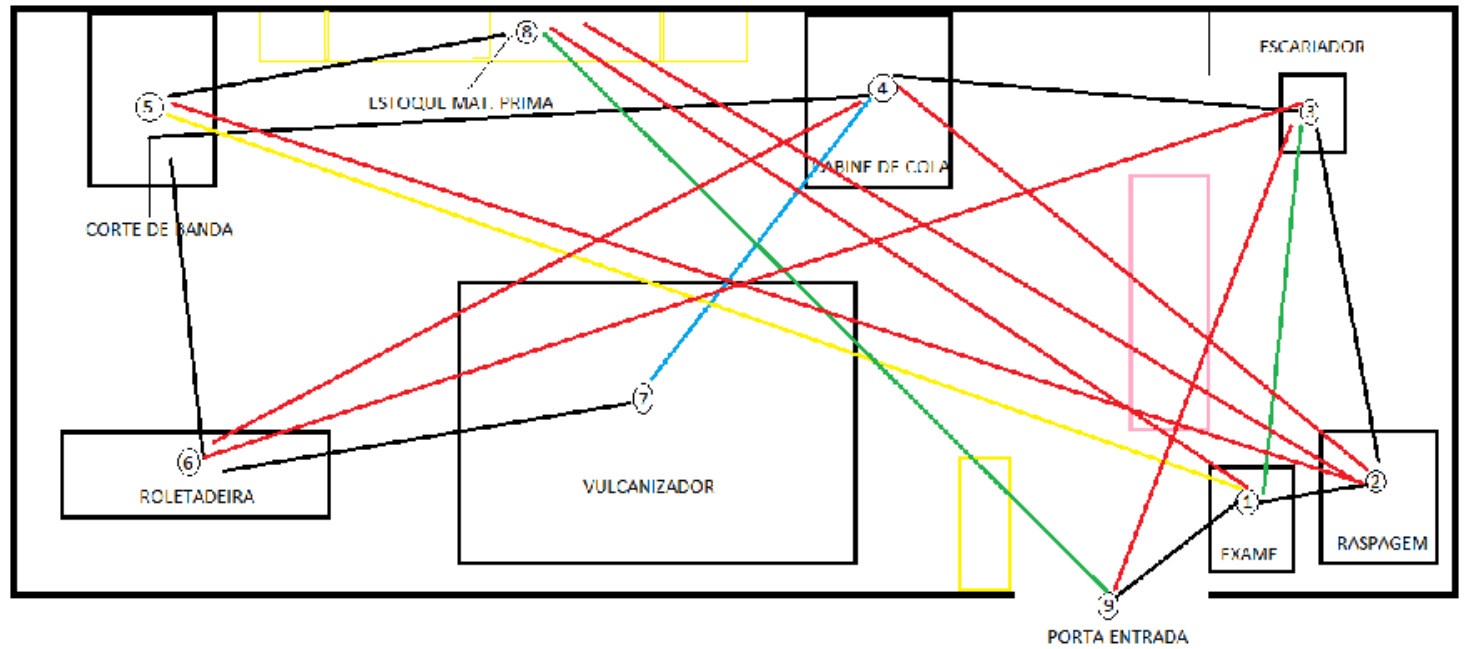

LAYOUT PROPOSTO B:

MÁQUINAS = - BALCÕO ENTR/DNE SNIDAN =

FAIXA. LUMINOSA $=$ PRATILEIRA ESTOQ. MAT. PRIMA

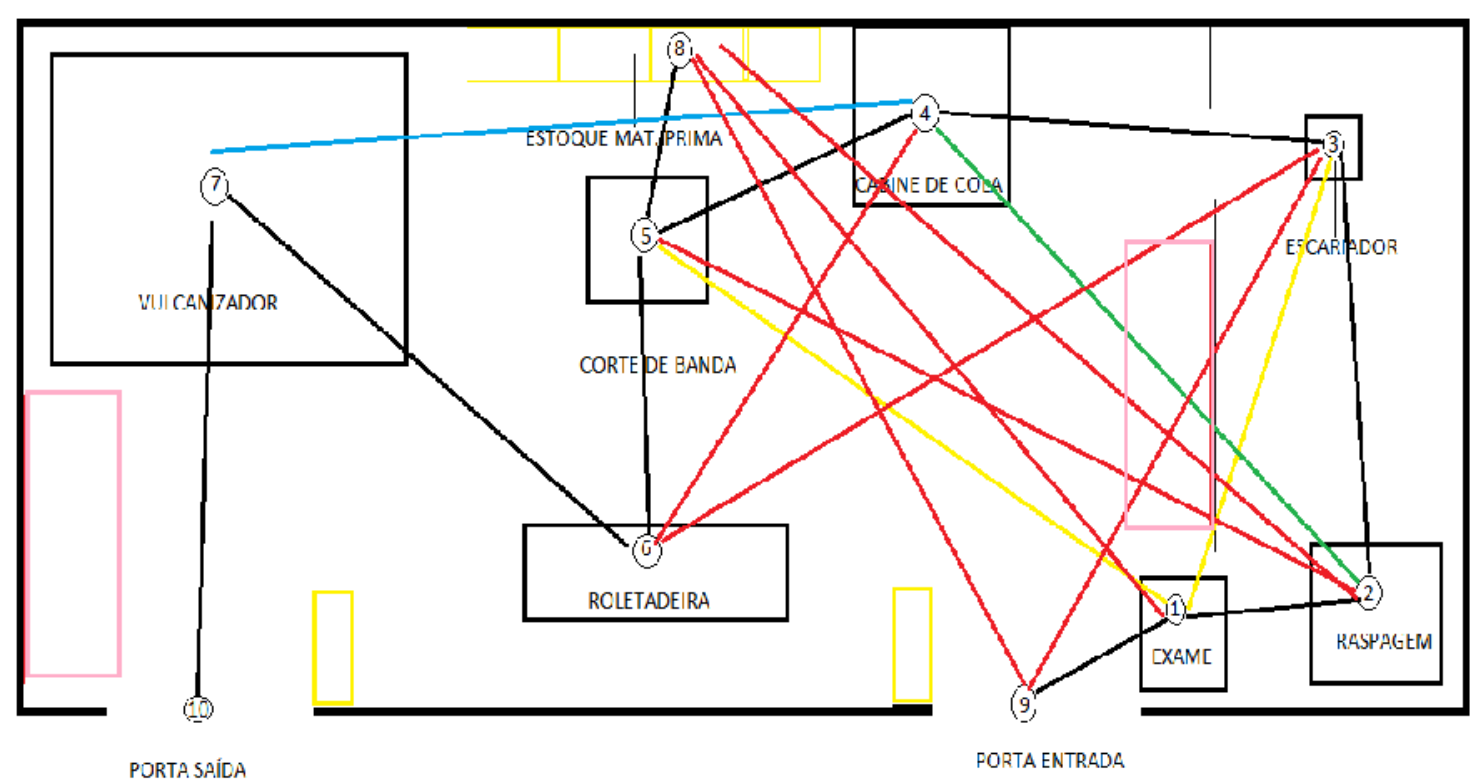

Fonte: Autores, 2010. 


\section{APÊNDICE V - AVALIAÇÃO DO ARRANJO FÍSICO}

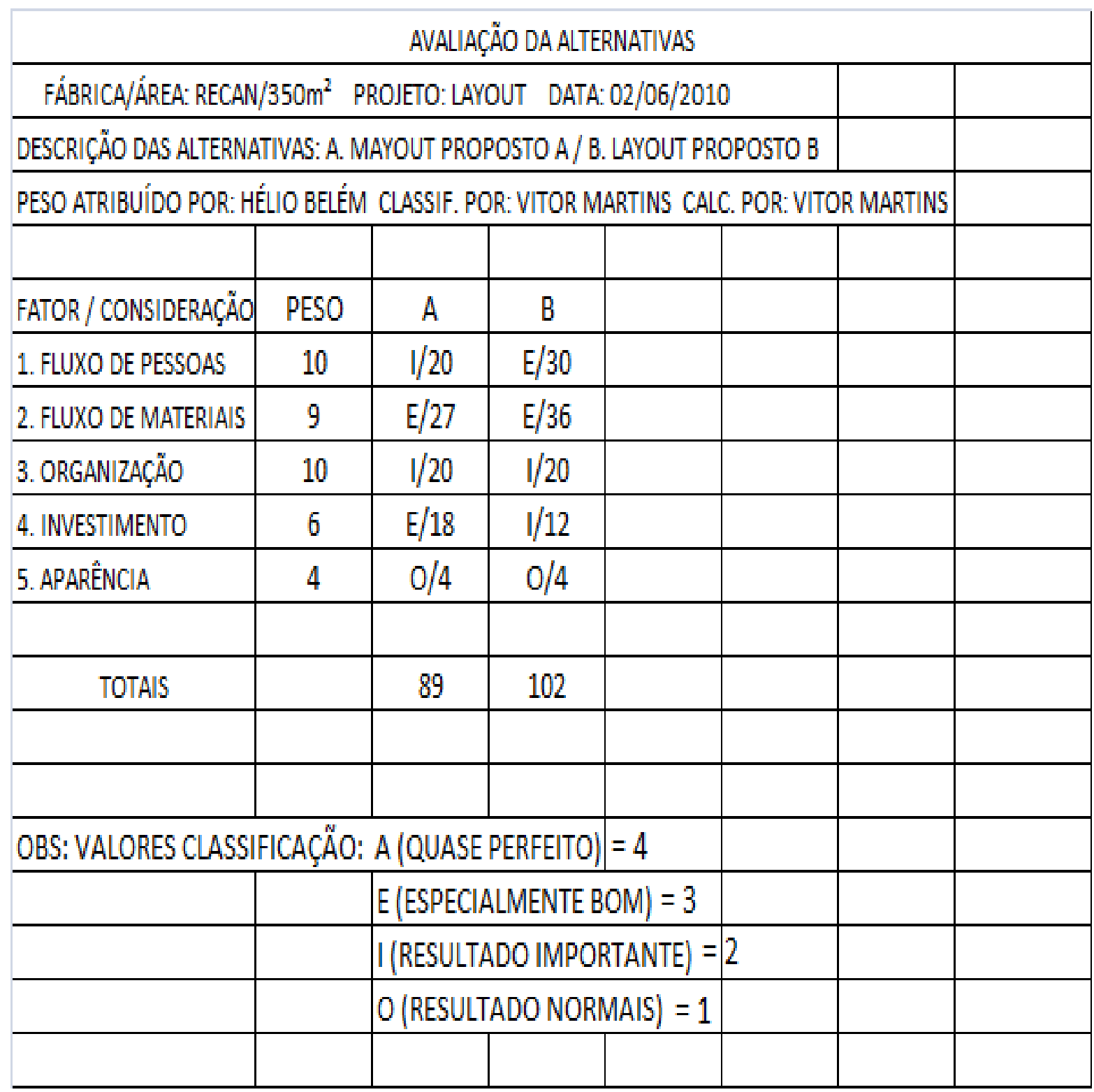

Fonte: Autores, 2010. 